\title{
Targeted Accrual Standard Cancer Center Information Summary
}

National Cancer Institute

\section{Source}

National Cancer Institute. Targeted Accrual Standard Cancer Center Information

Summary. NCl Thesaurus. Code C39525.

The Targ eted Accrual, Standard Cancer Center Information Summary for Cancer Center Support Grant Application, is the total number of patients needed for the entire clinical trial as stated in the protocol. Not a targeted range, but the number of patients the Cancer Center expects to accrue over the next 12 months of the reporting period should be indicated in the document. 